\title{
Selection of anti-cancer-associated gene single-chain variable fragments derived from gastric cancer patients using ribosome display
}

\author{
LIN XIN* ${ }^{*}$ JIAQING CAO* , CHUAN LIU, FEI ZENG, HUA CHENG, XIAOYUN HU, \\ PEIQIAN ZHU and JIANGHUA SHAO
}

Department of General Surgery, The Second Affiliated Hospital of Nanchang University, Nanchang, Jiangxi 330006, P.R. China

Received January 24, 2013; Accepted May 20, 2013

DOI: $10.3892 / \mathrm{mmr} .2013 .1502$

\begin{abstract}
The aim of this study was to construct a human single-chain variable fragment (scFv) gene library for gastric cancer, from which human anti-cancer-associated gene (CAGE) scFvs are selected. Human lymphocytes were isolated from the peripheral blood of 10 gastric cancer patients and whole human heavy and light chain genes were cloned by reverse transcription-polymerase chain reaction (RT-PCR). $\mathrm{V}_{\mathrm{H}}$ and $\mathrm{V}_{\mathrm{L}}$ were rearranged randomly by splicing by overlap extension PCR. The ribosome complexes were enriched against the recombinant CAGE protein conjugated to magnetic beads. $\mathrm{scFv}$ antibodies were evaluated by western blot analysis, and affinity constants in a solution of antigen-antibody complexes were determined by enzyme-linked immunosorbent assay. An scFv library was constructed using the peripheral blood lymphocytes. The expressed $\mathrm{scFv}$ proteins from the ternary ribosome complexes were analyzed by western blot analysis and the affinity [equilibrium dissociation constant $\left(\mathrm{K}_{\mathrm{D}}\right)$ ] of $\mathrm{scFv}$ for CAGE was determined to be $7.6 \times 10^{-8} \mathrm{M}$. The ribosome display technique is efficient for selecting a fully human antibody fragment from a patient-derived gene pool.
\end{abstract}

\section{Introduction}

As a novel cancer/testis antigen, cancer-associated gene (CAGE) was originally isolated by serological analysis of a cDNA expression library (SEREX) with serum from a patient with gastric cancer (1). CAGE is known to be widely expressed among cancer cell lines and cancer tissues, yet restricted to testis tissue among normal tissues (2-4). Cancer/testis antigens

Correspondence to: Professor Lin Xin, Department of General Surgery, The Second Affiliated Hospital of Nanchang University, 1 Minde Road, Nanchang, Jiangxi 330006, P.R. China

E-mail: linxincn@yeah.net

${ }^{*}$ Contributed equally

Key words: ribosome display, single-chain variable fragment, cancer-associated gene, gastric cancer, antibody engineering have the notable property of being immunogenic in cancer patients and are considered promising targets for cancer vaccines due to their restricted expression pattern (5). Thus, anti-CAGE antibodies are applicable for payload delivery. Particularly in oncology, anti-CAGE antibodies may be combined with cytotoxic entities that have limited selectivity.

Traditionally, monoclonal antibodies (mAbs) are produced through rodent immunization using hybridoma technology. However, this approach is laborious and poses difficulties in generating antibodies against self-antigens. In recent years, in vitro display techniques, including phage and ribosome display, have become a platform technology for the design, selection and production of reagents for targeted therapies in cancer (6). Ribosome display has a number of advantages over phage display. A number of the limitations of phage display including the inability to select antibodies under conditions different from the cell environment, problems with the selection of proteins that are toxic, cells circumventing selection pressure and low transformation efficiency, may be circumvented using in vitro ribosome display (7). Ribosome display enables rapid and easy screening to isolate specific novel binders to target ligands. Over the past decade, ribosome display has been widely used for the selection of human antibodies for therapeutic intervention in various cancers (8-10). In the present study, we describe the construction of a single-chain variable fragment (scFv) antibody library and selection of a fully human antibody fragment from a gastric cancer patient-derived gene pool by in vitro ribosome display technology.

\section{Materials and methods}

Construction of the scFv library. Peripheral blood lymphocytes were isolated from 10 gastric cancer patients who initially did not receive chemotherapy. All patients provided a participant information statement and informed consent. This study was approved by the Human Ethics Committee of Nanchang University School of Medicine (Jiangxi, China). Total RNA was isolated individually from peripheral blood lymphocytes using an RNA purification kit for amplification of the $\mathrm{scFv}$ library. Primers were designed as previously described (11), with certain modifications for the construction of ribosome 
Table I. Oligodeoxynucleotide primers used for construction of the library.

A, Primers for generating $\mathrm{V}_{\mathrm{H}^{-}}$-linker fragments.

Upstream primer sequence (5'-3')
$\mathrm{HuV}_{\mathrm{H}} 1 \mathrm{~b}-7 \mathrm{a} /$ reverse
GAG(A/G)TGCAGCTGGTGCA(A/G)TCTGG
$\mathrm{HuV}_{\mathrm{H}} 1 \mathrm{c} /$ reverse
(G/C)AGGTCCAGCTGGT(A/G)CAGTCTGG
$\mathrm{HuV}_{\mathrm{H}} 2 \mathrm{~b} /$ reverse
CAG(A/G)TCACCTTGAAGGAGTCTGG
$\mathrm{HuV}_{\mathrm{H}} 3 \mathrm{~b} /$ reverse
(G/C)AGGTGCAGCTGGTGGAGTCTGG
$\mathrm{HuV}_{\mathrm{H}} 3 \mathrm{c} /$ reverse
GAGGTGCAGCTGGTGGAG(A/T)C(C/T)GG
$\mathrm{HuV}_{\mathrm{H}} 4 \mathrm{~b} /$ reverse
CAGGTGCAGCTACAGCAGTGGGG
$\mathrm{HuV}_{\mathrm{H}} 4 \mathrm{c} /$ reverse
CAG(G/C)TGCAGCTGCAGGAGTC(G/C)GG
$\mathrm{HuV}_{\mathrm{H}} 5 \mathrm{~b} /$ reverse
GA(A/G)GTGCAGCTGGTGCAGTCTGG
$\mathrm{HuV}_{\mathrm{H}} 6 \mathrm{a} /$ reverse
CAGGTACAGCTGCAGCAGTCAGG

Downstream primer sequence (5'-3')

HuIgM linker/for

GGAGACGAGGGGGAAAAGGGTTGG

$\mathrm{B}$, Primers for generating $\mathrm{V} \kappa$ light chain.

Upstream primer sequence (5'-3')

$\mathrm{Hu} \mathrm{V \kappa} 1 \mathrm{~b} /$ reverse

$\mathrm{Hu} \mathrm{V \kappa} 2 /$ reverse

CTTTTCCCCCTCGTCTCCGACATCCAG(A/T)TGACCCAGTCTCC

$\mathrm{Hu} \mathrm{V \kappa} 3 \mathrm{~b} /$ reverse

CTTTTCCCCCTCGTCTCCGATGTTGTGATGACTCAGTCTCC

$\mathrm{Hu} \mathrm{V} \kappa 4 \mathrm{~b} /$ reverse

CTTTTCCCCCTCGTCTCCGAAATTGTG(A/T)TGAC(A/G)CAGTCTCC

$\mathrm{Hu} \mathrm{V} \kappa 5 /$ reverse

CTTTTCCCCCTCGTCTCCGATATTGTGATGACCCACACTCC

$\mathrm{Hu} \mathrm{V \kappa 6/reverse}$

CTTTTCCCCCTCGTCTCCGAAACGACACTCACGCAGTCTCC

CTTTTCCCCCTCGTCTCCGAAATTGTGCTGACTCAGTCTCC

Downstream primer sequence (5'-3')

$\mathrm{HuC \kappa} /$ for

GCTCTAGA ACACTCTCCCCTGTTGAAGCT

$\mathrm{C}$, Primers for generating $\mathrm{V}_{\lambda}$ fragment.

Upstream primer sequence (5'-3')

$\mathrm{Hu} \mathrm{V}_{\lambda} 1 \mathrm{a} /$ reverse

CTTTTCCCCCTCGTCTCCCAGTCTGTGCTGACTCAGCCACC

$\mathrm{Hu} \mathrm{V}_{\lambda} 1 \mathrm{~b} /$ reverse

CTTTTCCCCCTCGTCTCCCAGTCTGTG(C/T)TGACGCAGCCCGCC

$\mathrm{Hu} \mathrm{V}_{\lambda} 1 \mathrm{c} /$ reverse

CTTTTCCCCCTCGTCTCCCAGTCTGTCGTGACGCAGCCGCC

$\mathrm{Hu} \mathrm{V}_{\lambda} 2 /$ reverse

$\mathrm{Hu} \mathrm{V}_{\lambda} 3 \mathrm{a} /$ reverse

CTTTTCCCCCTCGTCTCCCA(A/G)TCTGCCCTGACTCAGCCT

$\mathrm{Hu} \mathrm{V}_{\lambda} 3 \mathrm{~b} /$ reverse

CTTTTCCCCCTCGTCTCCTCCTATG(A/T)GCTGACTCAGCCACC

$\mathrm{Hu} \mathrm{V}_{\lambda} 4 /$ reverse

CTTTTCCCCCTCGTCTCCTCTTCTGAGCTGACTCAGGACCC

$\mathrm{Hu} \mathrm{V}_{\lambda} 5 /$ reverse

CTTTTCCCCCTCGTCTCCCACGTTATACTGACTCAACCGCC

CTTTTCCCCCTCGTCTCCCAGGCTGTGCTGACTCAGCCGTC

$\mathrm{Hu} \mathrm{V}_{\lambda} 6 /$ reverse

CTTTTCCCCCTCGTCTCCAATTTTATGCTGACTCAGCCCCA

$\mathrm{Hu} \mathrm{V}_{\lambda} 7-8 /$ reverse

CTTTTCCCCCTCGTCTCCCAG(A/G)TCGTGGTGAC(C/T)CAGGAGCC

$\mathrm{Hu} \mathrm{V}_{\lambda} 9 /$ reverse

CTTTTCCCCCTCGTCTCCC(A/T)GCCTGTGCTGACTCAGCC(A/C)CC

Downstream primer sequence $\left(5^{\prime}-3^{\prime}\right)$

$\mathrm{HuJ}_{\lambda} /$ forward

GCAAGATGGTGCAGCCACACCTA(A/G)(A/G)ACGGTGAGCTTGGTC

D, Primers for generating full-length construct ${ }^{\mathrm{a}}$.

Upstream primer sequence (5'-3')

$\mathrm{T} 7 \mathrm{Ab} /$ reverse

GCAGC TAATACGACTCACTATAGGAACAGA CCACCATG

(C/G)AGGT(G/C)CA(G/C)CTCGAG(C/G)AGTCTGG

Downstream primer sequence $\left(5^{\prime}-3^{\prime}\right)$

$\mathrm{HuC \kappa} /$ forward

GCTCTAGAACACTCTCCCCTGTTGAAGCT 
Table I. Continued.

E, Primers for generating constant region $(\mathrm{C} \kappa)$ of $\kappa$ light chain ${ }^{\mathrm{b}}$.

Upstream primer sequence (5'-3')

$\mathrm{HuC \kappa /reverse}$

ACTGTGGCTGCACCATCTG

Downstream primer sequence (5'-3')

$\mathrm{HuC \kappa /forward}$

GCTCTAGAACACTCTCCCCTGTTGAAGCT

${ }^{\mathrm{a}} \mathrm{T} 7$ promoter sequence is italicized. The Kozak sequence is indicated in bold. Initiation codon ATG is underlined. Underlined italics indicate restriction sites for cloning. ${ }^{b}$ Underlined italics indicate a restriction site for cloning.

display libraries (Table I). First-strand cDNA was synthesized and $\mathrm{V}$ genes were amplified using suitable primers. Agarose gel electrophoresis revealed bands of the expected sizes. Splicing by splicing overlap extension polymerase chain reaction (PCR) led to a full-length human $\mathrm{scFv}$ repertoire linking the heavy and light chains. ScFv antibody libraries in the format of $\mathrm{V}_{\mathrm{H}} / \mathrm{K}$ and $\mathrm{V}_{\mathrm{H}} / \mathrm{V}_{\lambda}-\mathrm{C} \kappa$ were constructed for ribosome display.

Antibody-ribosome-mRNA (ARM) ribosome display. The eukaryotic ribosome display was performed as described previously (12), with certain modifications. The PCR libraries were expressed in a coupled rabbit reticulocyte lysate system to generate ARM complexes. The reaction was performed in a volume of $50 \mu \mathrm{l}$ containing $40 \mu \mathrm{l}$ TNT T7 Quick for PCR DNA, up to $5 \mu \mathrm{g}$ PCR DNA, $1 \mu 11 \mathrm{mM}$ methionine,

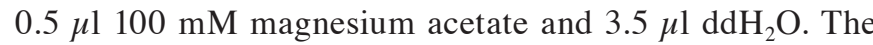
mixture was incubated in a siliconized tube at $30^{\circ} \mathrm{C}$ for $60 \mathrm{~min}$. Forty units RNase-free DNase I were added to the mixture together with $6 \mu \mathrm{l} 10 \mathrm{X}$ DNase I digestion buffer and $\mathrm{ddH}_{2} \mathrm{O}$, yielding a final volume of $60 \mu \mathrm{l}$. The mixture was then incubated at $30^{\circ} \mathrm{C}$ for an additional $15 \mathrm{~min}$. Cold $\left(4^{\circ} \mathrm{C}\right)$ phosphate-buffered saline (PBS; $60 \mu \mathrm{l}$ ) was added prior to antigen selection. Antigen-linked Dynabeads $(2 \mu \mathrm{g})$ were then added and the mixture was incubated at $4^{\circ} \mathrm{C}$ for $2 \mathrm{~h}$ with gentle agitation to select a CAGE-specific antibody fragment. The beads were collected magnetically and then washed three times with cold washing buffer (PBS, $1 \%$ Tween-20, and $5 \mathrm{mM}$ magnesium acetate), followed by washing twice with cold $\mathrm{ddH}_{2} \mathrm{O}$. The beads were collected by magnetic particle clutch and resuspended in $10 \mu \mathrm{l}$ nuclease-free $\mathrm{dd}_{2} \mathrm{O}$ for reverse transcription (RT)-PCR to recover antigen-selected mRNA. The beads were stored at 4 or $-20^{\circ} \mathrm{C}$.

The selected mRNA was reverse transcribed to cDNA using a PrimeScript ${ }^{\circledR}$ One Step RT-PCR Kit (ver. 2) for $30 \mathrm{~min}$ at $50^{\circ} \mathrm{C}$ for the reverse transcription and then for 2 min at $94^{\circ} \mathrm{C}$ for deactivation of the reverse transcriptase. The obtained cDNA was amplified in a $50 \mu \mathrm{l}$ PCR mixture for 30 cycles $\left(30 \mathrm{sec}\right.$ at $94^{\circ} \mathrm{C}, 30 \mathrm{sec}$ at $55^{\circ} \mathrm{C}$ and $1 \mathrm{~min}$ at $72^{\circ} \mathrm{C}$ ) with T7A1 (5'-GCAGCTAATACGACTCACTATAGAACA GACCACCATG-3') and Hu1 (5'-GCTCAGCGTCAGGGT GCTGCT-3'). For nested PCR, different downstream primers for subsequent cycles were used to enrich production: $\mathrm{Hu} 2$ (5'-CTCTCCTGGGAGTTACC-3') in the second cycle and Hu3 (5'-GAAGACAGATGGTGCAGC-3') in the third cycle. Purified products were applied to the subsequent selection round.
Cloning and expression. The DNA generated using the above-described steps was digested with XhoI and XbaI and ligated into the vector pBluescript $\mathrm{SK}^{+}$for periplasmic expression of the antibody fragment. Escherichia coli ( $E$. coli) BL21 containing the expression plasmid was grown in $20 \mathrm{ml} 2 \mathrm{X}$ tryptone-yeast extract (TY; $16 \mathrm{~g}$ tryptone; $10 \mathrm{~g}$ yeast extract, $5 \mathrm{~g} \mathrm{NaCl}$ ) medium containing $100 \mu \mathrm{g} / \mathrm{ml}$ ampicillin and $0.5 \%$ glucose at $37^{\circ} \mathrm{C}$ overnight. Following centrifugation at $300 \mathrm{x} \mathrm{g}$ for $10 \mathrm{~min}$, the bacterial pellet was induced by resuspension in $50 \mathrm{ml}$ fresh $2 \mathrm{X}$ TY containing $100 \mu \mathrm{g} / \mathrm{ml}$ ampicillin and $0.5 \mathrm{mM}$ isopropylthio- $\beta$-galactoside (IPTG) and then grown at room temperature $\left(20-25^{\circ} \mathrm{C}\right)$ for $5-7 \mathrm{~h}$. The bacteria were then harvested by centrifugation at $300 \mathrm{x} \mathrm{g}$ for $10 \mathrm{~min}$ and the pellet was either stored at $-20^{\circ} \mathrm{C}$ or used immediately. The pellet was first washed with $1 \mathrm{ml} 20 \%(\mathrm{w} / \mathrm{v})$ sucrose, $0.3 \mathrm{M}$ Tris- $\mathrm{HCl}$ ( $\mathrm{pH} 8.0$ ) and $1 \mathrm{mM}$ ethylenediaminetetraacetic acid (EDTA) to prepare a periplasmic extract. Following centrifugation, the bacteria were subjected to osmotic shock by rapidly mixing with $1 \mathrm{ml}$ ice-cold $0.5 \mathrm{mM}$ $\mathrm{MgCl}_{2}$ and leaving on ice for $10 \mathrm{~min}$ with periodic agitation. The supernatant periplasmic fraction containing the soluble $\mathrm{scFv}$ was recovered by centrifugation at $13,000 \mathrm{x} \mathrm{g}$ for $10 \mathrm{~min}$ at room temperature. Recombinant protein was further purified by affinity chromatography using Ni-NTA spin kits. Following binding of the protein to Ni-NTA agarose, the column was washed with increasing concentrations of imidazole. The expressed protein was eluted with $200 \mathrm{mM}$ imidazole and dialyzed overnight in PBS at $4^{\circ} \mathrm{C}$.

Immunoblot analysis. The purified periplasmic extracts from selected anti-CAGE-producing clones were subjected to sodium dodecyl sulfate polyacrylamide gel electrophoresis (SDS-PAGE) on $12 \%$ polyacrylamide gel. Following SDS-PAGE, the gel was transferred to a nitrocellulose membrane $[2 \%(\mathrm{w} / \mathrm{v})$ skimmed milk in PBS]. The transblotted membrane was blocked for $1 \mathrm{~h}$ at room temperature with blocking solution and then incubated for $1 \mathrm{~h}$ at room temperature with peroxidase-conjugated mouse anti-His tag (1/1000 dilution with blocking solution). 4-Chloro-1-naphthol was used as a peroxidase substrate to visualize the immunoreactivity. Protein concentration was determined using the BCA protein assay kit and purity was assessed with SDS-PAGE analysis.

Determination of $s c F v$ titer and affinity constant. The equilibrium dissociation constant $\left(\mathrm{K}_{\mathrm{D}}\right)$ value of $\mathrm{scFv}$ antibodies was 
determined in the solution phase by enzyme-linked immunosorbent assay (ELISA) $(13,14)$. A 96 -well plate was first coated with $5 \mu \mathrm{g} / \mathrm{ml}$ CAGE protein and then serially diluted scFv protein in $2 \%$ skimmed milk was added at $37^{\circ} \mathrm{C}$ for $1 \mathrm{~h}$. The bound antibodies were detected with normal ELISA. The concentration of $\mathrm{scFv}$ antibodies presenting $50 \%$ of the maximum antigen-binding activity was used in competitive ELISA, which was performed on immobilized CAGE as described above, with the exception that CAGE at various concentrations was mixed with a constant amount of antibody in $100 \mathrm{mM}$ PBS (pH 7.4) supplemented with $10 \mathrm{mg} / \mathrm{ml}$ bovine serum albumin (BSA). The antibody concentration was derived using ELISA as mentioned above. After overnight incubation at room temperature, $50 \mu \mathrm{l}$ each mixture was transferred into the well, coated with CAGE and incubated for $1 \mathrm{~h}$ at $37^{\circ} \mathrm{C}$. After washing, the bound $\mathrm{scFv}$ antibodies were detected as above in triplicate and their affinity was calculated using the Scatchard analysis equation.

Sequencing analysis. Plasmid DNA from anti-CAGEproducing clones was isolated from E. coli BL21. The scFv DNA was sequenced using the dideoxy method with the pBluescript $\mathrm{SK}^{+}$sequence primer set in an ABI Prism automated sequencing machine system.

\section{Results}

Antibody library construction. In this study, a large non-immune ribosome display antibody library was established for routine isolation of a high-affinity human $\mathrm{scFv}$ antibody to the CAGE antigen. Purified lymphocytes from blood samples were obtained from 10 gastric cancer patients for amplification of the scFv library. Following total RNA isolation, first-strand cDNA synthesis and amplification of $\mathrm{V}$ genes with their corresponding primers were performed. Agarose gel electrophoresis revealed bands of the expected sizes (Fig. 1). Splicing by overlap extension PCR was then used to generate full-length $\mathrm{scFv}$ gene templates, i.e., $\mathrm{V}_{\mathrm{H}} / \mathrm{\kappa}$ and $\mathrm{V}_{\mathrm{H}} / \mathrm{V}_{\lambda}-\mathrm{C} \kappa$, which were detected by gel electrophoresis (Fig. 2). Although variable regions in the light and heavy chains of the $\mathrm{scFv}$ genes were different, their upstream primer, downstream primer and linker were the same. Thus, these scFvs had an identical sequential pattern graph. DNA sequencing of randomly selected clones confirmed in-frame cloned V genes of human origin derived from various V-gene families (data not shown).

ARM ribosome display. The scFv library was expressed in vitro in the rabbit reticulocyte coupled transcription/translation system to generate ternary RNA-ribosome-scFv complexes. The ribosome complexes were enriched by the binding of $\mathrm{scFv}$ antibody to recombinant CAGE protein-conjugated Dynabeads. Following RT-PCR recovery of the selected RNA in the complexes, the small DNA band was detected following three rounds of subtractive panning, as shown by the results of agarose gel electrophoresis (Fig. 3). For nested PCR, we used the downstream primer $\mathrm{Hu} 2$ in the second cycle and $\mathrm{Hu} 3$ in the third cycle in order that the recovered DNA became progressively shorter in each cycle. The shortening only affected the constant domain of the $\kappa$-light chain.
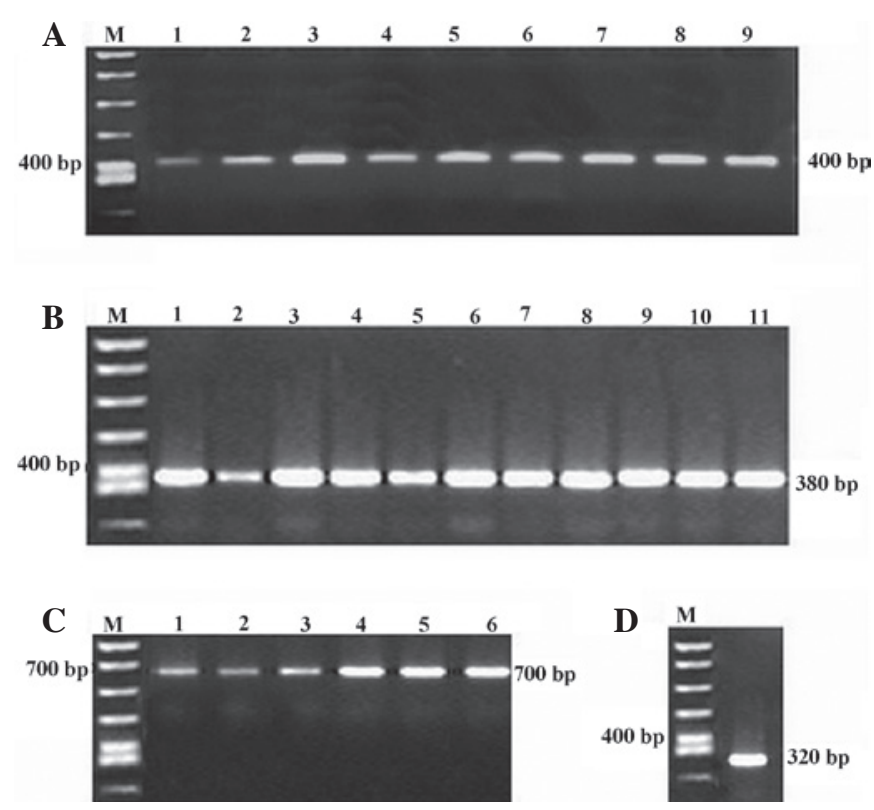

Figure 1. Electrophoretogram of the production of $\mathrm{V}_{\mathrm{H}}$ linker, $\mathrm{V}_{\lambda}, \mathrm{V}_{\kappa}$ and $\mathrm{C} \kappa$ (A) Polymerase chain reaction (PCR) products of the $\mathrm{V}_{\mathrm{H}}$ repertoire analyzed by electrophoresis on $1.5 \%$ agarose gel. (B) PCR products of the $V_{\lambda}$ repertoire analyzed by electrophoresis on $1.5 \%$ agarose gel. (C) PCR products of the VK repertoire analyzed by electrophoresis on $1.5 \%$ agarose gel. (D) PCR products of the $\mathrm{C} \kappa$ repertoire analyzed by electrophoresis on $1.5 \%$ agarose gel.
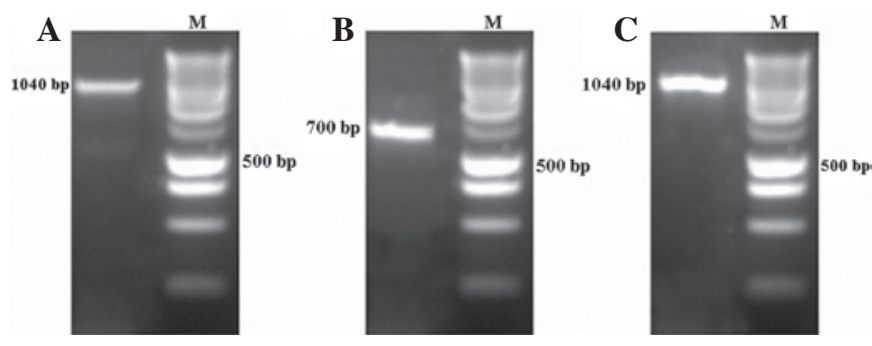

Figure 2. Electrophoretogram of the production of single-chain variable fragment (scFv). (A) Polymerase chain reaction (PCR) products of the assembled $\mathrm{V}_{\mathrm{H}} / \kappa$ DNA library analyzed by electrophoresis on $1.5 \%$ agarose gel. (B) PCR products of the assembled $\mathrm{V}_{\lambda}-\mathrm{C} \kappa \mathrm{DNA}$ library analyzed by electrophoresis on $1.5 \%$ agarose gel. (C) PCR products of the assembled $\mathrm{V}_{\mathrm{H}} / \mathrm{V}_{\lambda}$-C $\mathrm{C}$ DNA library analyzed by electrophoresis on $1.5 \%$ agarose gel.

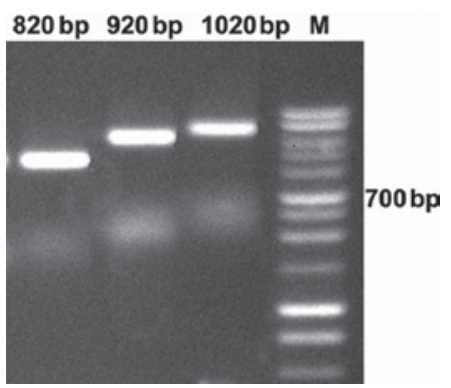

Figure 3. Selection of human $\mathrm{V}_{\mathrm{H}} / \kappa$ or $\mathrm{V}_{\mathrm{H}} / \mathrm{V}_{\lambda}-\mathrm{C} \kappa$ fragments against cancerassociated gene (CAGE) over 3 cycles of antibody-ribosome-mRNA (ARM) display. Agarose gel analysis (1.5\%) of DNA recovered by reverse transcription-polymerase chain reaction (RT-PCR) after each ARM display cycle.

Western blot analysis. After three rounds of panning, the CAGE-specific scFv antibody genes were digested and ligated into the expression vector. The expressed scFv antibodies were 


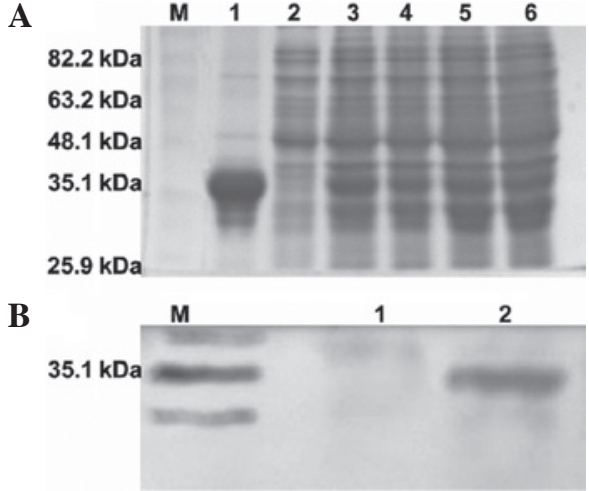

Figure 4. (A) Sodium dodecyl sulfate-polyacrylamide gel electrophoresis (SDS-PAGE) of E. coli BL21 expression of anti-cancer-associated gene (CAGE) single-chain variable fragment (scFv) gene. M, marker of protein lane 1, purified anti-CAGE scFv; lane 2, lysates of uninduced total bacteria; lanes 3-6, crude lysates of bacteria with different levels of isopropylthio$\beta$-galactoside (IPTG) induction. (B) Western blot analysis of CAGE scFv-expressed protein. Lane 1, uninduced total bacterial proteins; lane 2, purified anti-CAGE scFv.

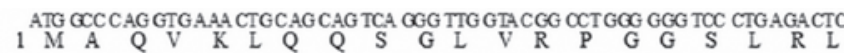

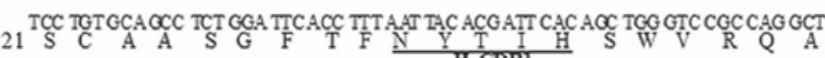
CCA GOG AAG GGO CTG GAG TGG GTC TCA GGI ATTGATCCC AOC AGT GAT TAT ACAT AAG TAC

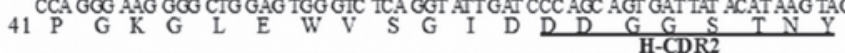

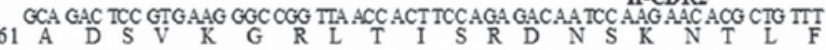

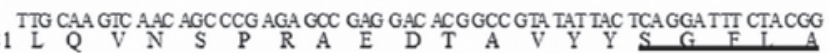
CCTTATTAC ACT ATG GAC TAC CCT TTT GAT ATC TOG GGC CAAGGGACAATGGTC AOC GTC

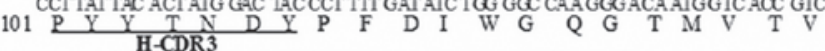
1 TCT TOG GGGGAGTGCA TCC GOC OCAACCCTTTTC OCC CTC GTC TCC AAA ATT GTG TTGACA CAG TCTCCA GCC ACCCTG TCT TTO TCT CA AGGG GACAGAGCCACC CTCTOCTGCAGGGCC 1 AGT GOC ACC TCA AGT ATA CGT TAT ATA TAT TACCAACAG AAA OCTGGC CAG OCTCCC AGG

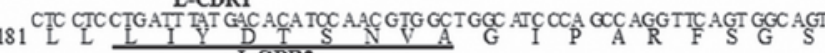
${ }_{1}$ GGG TCT GGGACA GAC TTCACT CTCACC ATC AGC AGC CTAGAG CCTGAAGAT TTT GCA GTI

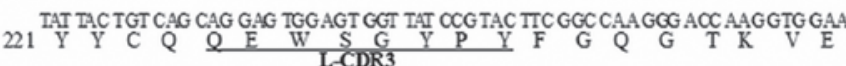
$\underset{\mathrm{K}}{\mathrm{AATCGGGCG}} \mathrm{ACT} \mathrm{TTC}_{\mathrm{V}}$

Figure 5. Nucleotide and derived amino acid sequences of the single-chain variable fragment $(\mathrm{scFv})$ gene.

collected from the periplasm of the bacteria and purified by affinity chromatography using Ni-NTA spin kits. The amount of the best-expressed $\mathrm{scFv}$ anti-CAGE proteins expressed in $E$. coli BL21 was $\sim 30 \%$ of the total bacterial proteins. SDS-PAGE results for the full-length fusion proteins are shown in Fig. 4A. The expression of $\mathrm{scFv}$ was confirmed by western blot analysis using anti-His tag antibodies (Fig. 4B). The selected $\mathrm{scFv}$ antibody presented a single band measuring $\sim 35 \mathrm{kDa}$ in size.

Dissociation constant of CAGE-specific scFvs and sequence analysis. According to the Scatchard analysis equation $\left[A_{0} /\left(A_{0}-A\right)=K_{\mathrm{D}} / A_{\mathrm{g}}+1\right.$, where $A_{0}$ is the absorbance when the antibody was incubated without any antigen, $A$ is the absorbance corresponding to free antibody following incubation with antigen and $A_{\mathrm{g}}$ is the free antigen concentration that is equal to the antigen obtained for experimentation considering a pseudo-first-order reaction], the $K_{\mathrm{D}}$ of $\mathrm{scFv}$ for CAGE was $7.6 \times 10^{-8} \mathrm{M}$. Fig. 5 shows the RT-PCR product sequence obtained following the third screening cycle and its deduced amino acid sequence. Complementarity determining regions (CDRs) are marked as per the Kabat definition.

\section{Discussion}

Gastric cancer is one of the most common malignancies in the digestive system. Chemotherapy remains the mainstay of treatment for advanced gastric cancer; however, its efficacy is modest. An understanding of the molecular biological mechanisms underlying the formation, progression and metastasis of advanced gastric cancer has enabled the use of this new approach to treat this disease in clinical practice. In recent years, molecular-targeted therapies have emerged as a novel approach to the treatment of gastric cancer (15). mAb-based cancer immunotherapy has attracted significant research interest. Immunoconjugate agents are obtained by coupling radioactive materials, chemotherapeutic agents and biotoxins with mAbs (16-18). The coupled agents produce antitumor effects by directing mAbs to the cell surface that expresses the corresponding antigen. The coupled agents also reduce the damage to normal tissues.

At present, therapeutic mAbs are one of the most rapidly growing components of the biopharmaceutical industry. Investigators have created large numbers of mouse mAbs to treat or diagnose human diseases. However, the availability of mouse mAbs has been greatly limited by their high immunogenicity in humans and rapid clearance due to the human anti-mouse antibody reactions that occur in patients (19). Thus, mouse mAbs have exhibited significantly limited and inefficient effector functions in clinical trials. To reduce the immunogenicity of mouse mAbs, an attempt has been made to establish methods to generate human-derived mAbs. Several methods for generating human mAbs have been established, including the phage and ribosome display methods, as well as transchromosome mice technology, in which human Ig genes are expressed (20). Ribosome display is considered to be one of the most promising biotechnologies among the next generation of display technologies (21). It is a technique used to perform in vitro protein evolution to create proteins that bind to a desired ligand (22). The process results in translated proteins associated with their mRNA progenitor, which is used as a complex to bind to an immobilized ligand in a selection step. scFv-ribosome-mRNA complexes bind to their specific antigens and non-specific complexes are removed by extensive washing. Eluted mRNAs from the remaining complexes are reverse transcribed to cDNA and reamplified by PCR. The outcome is a nucleotide sequence that may be used to create tightly binding proteins. In addition, ribosome display has advantages in selection from larger libraries and is capable of affinity maturation without any need for additional ligation, transformation or construction of a second library (23).

Together with the progression of genome medical science, an increasing number of target molecules in various diseases have been revealed. Cancer testis antigens are a unique class of tumor antigens expressed in a variety of cancer tissues but silent in normal tissues, with the exception of the testis. Due 
to their restricted gene expression in the testis and various malignancies, cancer testis antigens are potential defined targets for antigen-based vaccination and antigen-directed immunotherapy for the regulation of cancer growth (24). CAGE is a typical cancer/testis antigen that is overexpressed in gastric cancer tissues, whereas its expression in normal tissues is limited to the testis (25). Studies have shown that anti-CAGE IgG antibodies are present in the sera of patients with various cancers (26). Therefore, CAGE may be an ideal target for delivering cytotoxic agents to tumors.

In this study, we used ribosome display to select a fully human anti-CAGE scFv. Small antibody fragments, including Fab and $\mathrm{scFv}$, exhibit applicable pharmacokinetics for tissue penetration and full binding specificity as the antigen-binding surface is unaltered (27). A single-chain antibody library in the format of $\mathrm{V}_{\mathrm{H}} / \kappa$ and $\mathrm{V}_{\mathrm{H}} / \mathrm{V}_{\lambda}-\mathrm{C} \kappa$ was constructed using a PCR-based recombination method. Using this DNA library, we performed CAGE-specific scFv selection and enrichment by ribosome display. After three rounds of selection, antiCAGE scFv was cloned into an expression vector.

In vitro display techniques have certain potential advantages over in vivo display methods. These include ease of generating larger libraries, fewer biases than would be caused by cell expression and more facile application of round-by-round mutagenesis (28). In this study, we performed ribosome display, an in vitro display method, using an in vitro transcription and translation process. As the library size of a ribosome display is not limited by transformation, anti-CAGE $\mathrm{scFv}$ is more easily obtained from DNA libraries using ribosome display than by in vivo display methods. We used a rabbit reticulocyte lysate system since such a system has a lower level of RNase activity compared with the $E$. coli ribosome display system, rendering the selection conditions less complex. Moreover, eukaryotic conditions may improve the translation and/or folding efficiency of certain proteins. Therefore, our study is valuable as an example of antibody selection from an antibody library by ribosome display using a eukaryotic translation system.

Although we observed antigen-specific gene recovery by RT-PCR and monitored the enrichment rate during the selection procedure, our results suggest that three rounds are not sufficient for complete selection. One reason may be that stringent selection conditions are essential for the enrichment of specific binders (29). Low temperature and RNase-free conditions are required to maintain intact scFv-ribosomeRNA complexes. With the aim of developing more efficient selection in ribosome display using eukaryotic translation, we are currently studying the factors involved in maintaining ARM complexes. To the best of our knowledge, this is the first time that this technique has been used successfully for the direct generation of human scFv against CAGE. As the $\mathrm{scFv}$ originates from humans, it is expected to be less immunogenic.

In summary, a new human anti-CAGE scFv was isolated using in vitro ribosome display technology. The technological challenge of the ribosome display methodology is reflected in the screening process. Nevertheless, it successfully isolates a fully human antibody construct with specificity to a clinically relevant target antigen. It may provide the basis for the development of anti-scFv-drug conjugates for the proliferation and metastasis of gastric cancer cells.

\section{Acknowledgements}

The authors thank Dr Bing-Ya Liu and Wen-Tao Liu (Shanghai Institute of Digestive Surgery, Ruijin Hospital, Shanghai Jiao Tong University School of Medicine) for their technical assistance. This study was supported by the National Natural Science Foundation of China (no. 30960442).

\section{References}

1. Cho B, Lim Y, Lee DY, Park SY, Lee H, Kim WH, Yang H, Bang YJ and Jeoung DI: Identification and characterization of a novel cancer/testis antigen gene CAGE. Biochem Biophys Res Commun 292: 715-726, 2002.

2. Kim Y and Jeoung D: Role of CAGE, a novel cancer/testis antigen, in various cellular processes, including tumorigenesis, cytolytic T lymphocyte induction, and cell motility. J Microbiol Biotechnol 18: 600-610, 2008.

3. Kim Y, Park H, Park D, Lee YS, Choe J, Hahn JH, Lee H, Kim YM and Jeoung D: Cancer/testis antigen CAGE exerts negative regulation on p53 expression through HDAC2 and confers resistance to anti-cancer drugs. J Biol Chem 285: 25957-25968, 2010.

4. Por E, Byun HJ, Lee EJ, Lim JH, Jung SY, Park I, Kim YM, Jeoung DI and Lee H: The cancer/testis antigen CAGE with oncogenic potential stimulates cell proliferation by up-regulating cyclins D1 and E in an AP-1- and E2F-dependent manner. J Biol Chem 285: 14475-14485, 2010.

5. Caballero OL and Chen YT: Cancer/testis (CT) antigens: potential targets for immunotherapy. Cancer Sci 100: 2014-2021, 2009.

6. Filpula D: Antibody engineering and modification technologies. Biomol Eng 24: 201-215, 2007.

7. Dreier B and Plückthun A: Ribosome display: a technology for selecting and evolving proteins from large libraries. Methods Mol Biol 687: 283-306, 2011.

8. Rothe A, Nathanielsz A, Hosse RJ, Oberhäuser F, Strandmann EP, Engert A, Hudson PJ and Power BE: Selection of human anti-CD28 scFvs from a T-NHL related scFv library using ribosome display. J Biotechnol 130: 448-454, 2007.

9. Rothe A, Nathanielsz A, Oberhäuser F, von Pogge SE, Engert A, Hudson PJ and Power BE: Ribosome display and selection of human anti-cD22 scFvs derived from an acute lymphocytic leukemia patient. Biol Chem 389: 433-439, 2008.

10. Li F, Su P, Lin C, Li H, Cheng J and Shi D: Ribosome display and selection of human anti-placental growth factor $\mathrm{scFv}$ derived from ovarian cancer patients. Protein Pept Lett 17: 585-590, 2010.

11. He M, Cooley N, Jackson A and Taussig MJ: Production of human single-chain antibodies by ribosome display. Methods Mol Biol 248: 177-189, 2004.

12. He M and Taussig MJ: Antibody-ribosome-mRNA (ARM) complexes as efficient selection particles for in vitro display and evolution of antibody combining sites. Nucleic Acids Res 25: 5132-5134, 1997.

13. Friguet B, Chaffotte AF, Djavadi-Ohaniance L and Goldberg ME: Measurements of the true affinity constant in solution of antigenantibody complexes by enzyme-linked immunosorbent assay. J Immunol Methods 77: 305-319, 1985.

14. Yan XH and Xu ZR: Production of human single-chain variable fragment (scFv) antibody specific for digoxin by ribosome display. Indian J Biochem Biophys 42: 350-357, 2005.

15. Yoong J, Michael M and Leong T: Targeted therapies for gastric cancer: current status. Drugs 71: 1367-1384, 2011.

16. Andratschke M, Luebbers CW, Johannson V, Schmitt B, Mack B, Zeidler R, Lang S, Wollenberg B and Gildehaus FJ: Biodistribution of 131I-labeled anti-CK8 monoclonal antibody in HNSCC in xenotransplanted SCID mice. Anticancer Res 31: 3315-3321, 2011.

17. Kreitman RJ and Pastan I: Antibody fusion proteins: anti-CD22 recombinant immunotoxin moxetumomab pasudotox. Clin Cancer Res 17: 6398-6405, 2011.

18. Ricart AD: Antibody-drug conjugates of calicheamicin derivative: gemtuzumab ozogamicin and inotuzumab ozogamicin. Clin Cancer Res 17: 6417-6427, 2011.

19. Bernett MJ, Karki S, Moore GL, et al: Engineering fully human monoclonal antibodies from murine variable regions. J Mol Biol 396: 1474-1490, 2010. 
20. Yamashita M, Katakura Y and Shirahata S: Recent advances in the generation of human monoclonal antibody. Cytotechnology 55: $55-60,2007$

21. He M and Khan F: Ribosome display: next-generation display technologies for production of antibodies in vitro. Expert Rev Proteomics 2: 421-430, 2005.

22. Zahnd C, Amstutz P and Plückthun A: Ribosome display: selecting and evolving proteins in vitro that specifically bind to a target. Nat Methods 4: 269-279, 2007.

23. He M and Taussig MJ: Selection of recombinant antibodies by eukaryotic ribosome display. Methods Mol Biol 484: 193-205, 2008.

24. Suri A: Cancer testis antigens - their importance in immunotherapy and in the early detection of cancer. Expert Opin Biol Ther 6: 379-389, 2006.

25. Cho B, Lee H, Jeong S, Bang YJ, Lee HJ, Hwang KS, Kim HY, Lee YS, Kang GH and Jeoung DI: Promoter hypomethylation of a novel cancer/testis antigen gene CAGE is correlated with its aberrant expression and is seen in premalignant stage of gastric carcinoma. Biochem Biophys Res Commun 307: 52-63, 2003.
26. Iwata T, Fujita T, Hirao N, et al: Frequent immune responses to a cancer/testis antigen, CAGE, in patients with microsatellite instability-positive endometrial cancer. Clin Cancer Res 11: 3949-3957, 2005.

27. Accardi L and Di Bonito P: Antibodies in single-chain format against tumour-associated antigens: present and future applications. Curr Med Chem 17: 1730-1755, 2010.

28. Ullman CG, Frigotto L and Cooley RN: In vitro methods for peptide display and their applications. Brief Funct Genomics 10: 125-134, 2011.

29. Lee MS, Kwon MH, Kim KH, Shin HJ, Park S and Kim HI: Selection of scFvs specific for HBV DNA polymerase using ribosome display. J Immunol Methods 284: 147-157, 2004. 